\title{
Pattern of distribution of reactive localised hyperplasia of the oral cavity in patients at a tertiary health institution in Nigeria
}

\author{
Olujide O Soyele ${ }^{1}$, Adeola M Ladeji ${ }^{2}$, Kehinde E Adebiyi ${ }^{2}$, Olufunlola M Adesina ${ }^{1}$, \\ Adetayo O Aborisade ${ }^{3}$, Abiodun S Olatunji ${ }^{3}$, Henry A Adeola ${ }^{4,5}$
}

1. Department of Oral Maxillo-facial Surgery and Oral Pathology, Obafemi Awolowo University, Ile-Ife, Nigeria

2. Department of Oral Pathology and Oral Medicine, Faculty of Dentistry, Lagos State University College of Medicine, Ikeja, Lagos, Nigeria

3. Department of Oral and Maxillofacial Surgery and Oral Pathology, Obafemi Awolowo University Teaching Hospital Complex, Ile-Ife, Nigeria

4. Department of Oral and Maxillofacial Pathology, Faculty of Dentistry, University of the Western Cape and Tygerberg Hospital, Cape Town South Africa

5. Division of Dermatology, Department of Medicine, Faculty of Health Sciences and Groote Schuur Hospital, University of Cape Town, Cape Town South Africa.

\begin{abstract}
Background: Reactive localized hyperplastic lesions of the oral cavity (RHLs) are relatively common peripheral lesions which present as a range of clinically similar lesions at dental centers. Diagnosis can be challenging if dentists are unfamiliar with their clinicopathological across various populations.

Objective: This study reviews the pattern of distribution of RHLs of the oral mucosa in a hospital- the Obafemi Awolowo University Teaching Hospital Complex (OAUTHC), Ile-Ife.

Materials and methods: We reviewed 10 years data from the archives of the Department of Oral Maxillofacial Surgery and Oral Pathology, Obafemi Awolowo University, Nigeria. Information on RHLs were extracted and recorded on standardized data forms and analyzed using STATA.

Results: The most common lesions were pyogenic granuloma (43.7\%) and focal fibrous hyperplasia (39.7\%), respectively. RHLs were found to be more frequent in women $(66.7 \%)$ than men $(33.3 \%)$. The most common locations of involvement was the gingivae (84.6\%), and lesions were more common in the 9-29 year age group and the mean age was $37.7( \pm 21.1)$ years. The relationship between age group and reactive lesions was however not statistically significant.

Conclusion: The major benefit of this study is an improved knowledge of the frequency and distribution of oral reactive lesions in sub-Saharan Africa which may be highly beneficial when establishing a diagnosis and treatment plan in clinical practice. Keywords: Focal fibrous hyperplasia, oral mucosa, peripheral giant cell granuloma, peripheral ossifying fibroma, pyogenic granuloma, reactive hyperplasia.
\end{abstract}

DOI: https://dx.doi.org/10.4314/ahs.v19i1.45

Cite as: Soyele OO, Ladeji AM, Adebiyi KE, Adesina OM, Aborisade AO, Olatunji AS, et al. Pattern of distribution of reactive localised byperplasia of the oral cavity in patients at a tertiary health institution in Nigeria. Afri Health Sci. 2019;19(1). 1687-1694. bttps://dx.doi. org/10.4314/ abs. v19i1.45

\section{Corresponding author:}

Henry A Adeola,

Division of Dermatology,

Department of Medicine,

Faculty of Health Sciences

and Groote Schuur Hospital,

University of Cape Town,

Observatory 7925, Cape Town, South Africa

Email: henry.adeola@uct.ac.za

\section{Introduction}

The oral mucosal membrane is regularly exposed to various physical, chemical and microbial insults ${ }^{1-3}$. This exposure elicits various responses that may ultimately result in a range of reactive localized hyperplastic lesions; which present clinically as localized swellings of the mu$\operatorname{cosa}^{2,3}$. Histologically, reactive lesions are composed of exuberant fibrous connective tissue within which other components such as; vascular channels, multinucleated giant cells, inflammatory cells and bony or cementum-like

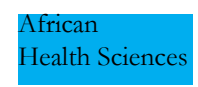

(C) 2019 Soyele et al. Licensee African Health Sciences. This is an Open Access article distributed under the terms of the Creative commons Attribution License (https://creativecommons.org/licenses/BY/4.0), which permits unrestricted use, distribution, and reproduction in any medium, provided the original work is properly cited. 
calcifications may be found ${ }^{2,3}$. In a low grade prolonged trauma, inflammation (which is the response of the body to insults) may result in the formation of granulation tissue which is characterized by the presence of endothelial cells, chronic inflam-matory cells (sometimes with inclusion of neutrophils), and proliferating fibroblasts- presenting clinically as an overgrowth called reactive hyperplasia ${ }^{4,5}$. These lesions are non-neoplastic but a chronic process in which an exuberant tissue response occurs following re $\neg$ pair ${ }^{6,7}$.

Chronic irritations by plaque and calculus, sharp edges of carious teeth, chronic habitual cheek biting, overhanging restorations, ill-fitting dental appliances and food impaction are readily identifiable as predisposing factors to reactive hyperplastic lesions (RHLs) ${ }^{1,2,7}$. These lesions can also be further aggravated by local factors in a background of systemic factors such as changes in hormonal levels (as observed in pregnancy and puberty) ${ }^{8,9}$. RHLs are mostly located in the gingivae and may present as pyogenic granuloma, fibrous epulis, peripheral giant cell granuloma, fibroepithelial polyp, peripheral ossifying fibroma, giant cell fibroma, and pregnancy epulis. They are less commonly present in other intraoral sites such as the cheek, tongue, palate and floor of the mouth ${ }^{5,7}$. It has been reported that up to $77 \%$ of lesions observed in the oral cavity are reactive in nature ${ }^{10}$. Esmeili et al, in their review stated that RHLs represent a group of most common oral lesions excluding caries, periodontal and periapical inflammatory disease Topographic pattern of distribution however varies with individual lesions. ${ }^{11}$

They have been categorized into four sub-groups which include pyogenic granuloma, peripheral ossifying fibroma, peripheral giant cell granuloma and fibrous hyperpla$\mathrm{sia}^{3}$. RHLs have variable clinical appearance varying from pinkish sessile or pedunculated non-ulcerated firm overgrowths to reddish ulcerated masses which can be a few millimeters to several centimeters in size.

Considering the diagnostic challenges associated with clinicopathological features of the highly heterogeneous RHLs across various populations, this study reviews the pattern of distribution of RHLs of the oral mucosa in a hospital- the Obafemi Awolowo University Teaching Hospital Complex (OAUTHC), Ile-Ife, which is a tertiary referral centre with a wide catchment area in Nigeria.

\section{Materials and methods}

This is a retrospective cross-sectional study in which all the existing records in the surgical archives of Oral Pathology unit of Oral and Maxillofacial Surgery and Oral Pathology Department, Obafemi Awolowo University, Ile-Ife, Nigeria, were extracted between 2006 and 2015, a period of 10 years. Patient records were assessed to select those with the histopathological diagnosis of reactive hyperplasticlesions according to recommended criteria by Daley et $\mathrm{al}^{12}$, and the classification of Kfir et $\mathrm{al}^{3}$.

\section{Inclusion and exclusion criteria}

The cases for inclusion in this study were those categorized as focal fibrous hyperplasia, pyogenic granuloma, peripheral ossifying fibroma and peripheral giant cell granuloma with available Haematoxylin and Eosin stained slides. Patients with adequate history from all age groups and both genders were included. Cases that did not meet these criteria were excluded. Furthermore, edentulous patients (who are non-denture users) and those taking immunosuppressive medications, anti-convulsants or calcium channel blockers were excluded from the study.

\section{Clinicopathological data}

Clinical data regarding age, gender, location of the lesion were obtained for each case from the patient records. Haematoxylin and Eosin stained slides of all the above mentioned lesions were retrieved to review and verify the specific diagnosis.

\section{Statistical analysis}

Data was analyzed using STATA (MP 13.1 for MacOS StataCorp, Lakeway Dr, College Station, Texas, USA). Descriptive statistics was carried out. Quantitative variable (Age) was expressed using mean, median, minimum, maximum and measures of variability. The qualitative variables (sex and site) of lesions were expressed as frequencies and percentages and further compared using likelihood ratio chi-square statistics.

\section{Results}

\section{General distribution of lesions}

From a total of 390 oral lesions in our archives, 78 cases $(20 \%)$ were RHLs. The most common oral RHLs was Pyogenic granuloma (PG), $(\mathrm{n}=34,43.7 \%)$, followed by Focal Fibrous Hyperplasia (FFH) $(\mathrm{n}=31,39.7 \%)$, Peripheral Ossifying Fibroma (POF) ( $\mathrm{n}=10,12.8 \%$ ) and the least common was Peripheral Giant Cell Granuloma (PGCG) ( $\mathrm{n}=3,3.8 \%)$. 
Age distribution

The mean age of the patients in this study was $37.7 \pm 21.1 \mathrm{yrs}$ (range 9-92 years). Most of the lesions were seen within the 9-29, 30-49 and 50-69 age range; while very few cases were seen above the age of 70 years (Table 1$)$.

Table 1: Distribution of oral reactive hyperplastic lesions within age group categories

\begin{tabular}{|l|c|c|c|c|c|}
\hline Age & $\begin{array}{l}\text { Pyogenic } \\
\text { Granuloma }\end{array}$ & $\begin{array}{l}\text { Focal Fibrous } \\
\text { Hyperplasia }\end{array}$ & $\begin{array}{l}\text { Peripheral Giant Cell } \\
\text { Granuloma }\end{array}$ & $\begin{array}{l}\text { Peripheral } \\
\text { Ossifying Fibroma }\end{array}$ & Total \\
\hline $\mathbf{9 - 2 9}$ & 14 & 14 & 0 & 3 & 31 \\
\hline $\mathbf{3 0 - 4 9}$ & 7 & 9 & 1 & 2 & 19 \\
\hline $\mathbf{5 0 - 6 9}$ & 10 & 6 & 0 & 3 & 19 \\
\hline $\mathbf{7 0 - 8 9}$ & 3 & 1 & 2 & 2 & 8 \\
\hline $\mathbf{9 0}$ & 0 & 1 & 0 & 0 & 1 \\
\hline Total & 34 & 31 & 3 & 10 & 78 \\
\hline
\end{tabular}

Gender distribution

Of all the patients examined, 52 (66.70\%) were female, $26(33 \%)$ were male, with a male: female ratio of $1: 2$. Fe- males were more commonly affected than males in all the lesions while PGCG and POF were exclusive to female patients (Table 2).

Table 2: Gender distribution of oral reactive hyperplastic lesions

\begin{tabular}{|l|c|c|c|c|c|}
\hline Gender & $\begin{array}{l}\text { Pyogenic } \\
\text { Granuloma }\end{array}$ & $\begin{array}{l}\text { Focal Fibrous } \\
\text { Hyperplasia }\end{array}$ & $\begin{array}{l}\text { Peripheral } \\
\text { Ossifying } \\
\text { Fibroma }\end{array}$ & $\begin{array}{l}\text { Peripheral } \\
\text { Giant Cell } \\
\text { Granuloma }\end{array}$ & Total \\
\hline Male & 14 & 12 & 0 & 0 & 26 \\
\hline Female & 20 & 19 & 10 & 3 & 52 \\
\hline Total & 34 & 31 & 10 & 3 & 78 \\
\hline
\end{tabular}




\section{Location}

Gingiva of the lower jaw was the most commonly affected site with 38 cases, followed by gingiva of the upper jaw
(28 cases), lip (6 cases), buccal mucosa and palate (2 cases each) and tongue (one case). All cases of PGCG and POF were limited to the gingiva except a case of POF which was observed in the palate (Table 3).

\section{Table 3: Site distribution of oral reactive hyperplastic lesions}

\begin{tabular}{|l|c|c|c|c|c|}
\hline Site & $\begin{array}{l}\text { Pyogenic } \\
\text { Granuloma }\end{array}$ & $\begin{array}{l}\text { Focal Fibrous } \\
\text { Hyperplasia }\end{array}$ & $\begin{array}{l}\text { PeripheralGia } \\
\text { nt Cell } \\
\text { Granuloma }\end{array}$ & $\begin{array}{l}\text { Peripheral } \\
\text { Ossifying } \\
\text { Fibroma }\end{array}$ & Total \\
\hline $\begin{array}{l}\text { Buccal } \\
\text { mucosa }\end{array}$ & 1 & 2 & 0 & 0 & 2 \\
\hline Palate & 0 & 1 & 0 & 1 & 2 \\
\hline Tongue & 0 & 1 & 0 & 0 & 1 \\
\hline Upper lip & 2 & 0 & 0 & 0 & 2 \\
\hline Lower lip & 1 & 3 & 0 & 0 & 4 \\
\hline $\begin{array}{l}\text { Gingiva } \\
\text { (Upper) }\end{array}$ & 14 & 10 & 1 & 3 & 28 \\
\hline $\begin{array}{l}\text { Gingiva } \\
\text { (lower) }\end{array}$ & 16 & 14 & 2 & 6 & 38 \\
\hline Total & 34 & 31 & 3 & 10 & 78 \\
\hline
\end{tabular}

\section{Clinicopathological findings}

PG is clinically an elevated and sometimes ulcerated red or purplish lesion which may be soft or firm. It bleeds easily due to its high vascularity, and may become firm and pinkish in appearance as it gets matured (with more connective tissue formation). Histological appearance of PG revealed an eroded or ulcerated surface epithelium (pyogenic membrane) that overlies a connective tissue stroma which contains vast numbers of thin endothelial-lined vascular channels engorged with red blood cells, with mixture of infiltrative inflammatory cells predominantly neutrophils, lymphocytes and plasma cells. Proliferating fibroblasts in spindle to plump shape were also seen within the stroma. Microscopically, POF presented an intact or ulcerated stratified squamous epithelium with dense fibrous stroma containing numerous fibroblasts. Formation of mineralized products that may include bone, cementum/dystrophic like calcification or a combination of both were also seen in association. Summary of histological findings of FFH, PG, POF and PGCG were presented in Figure 1. 

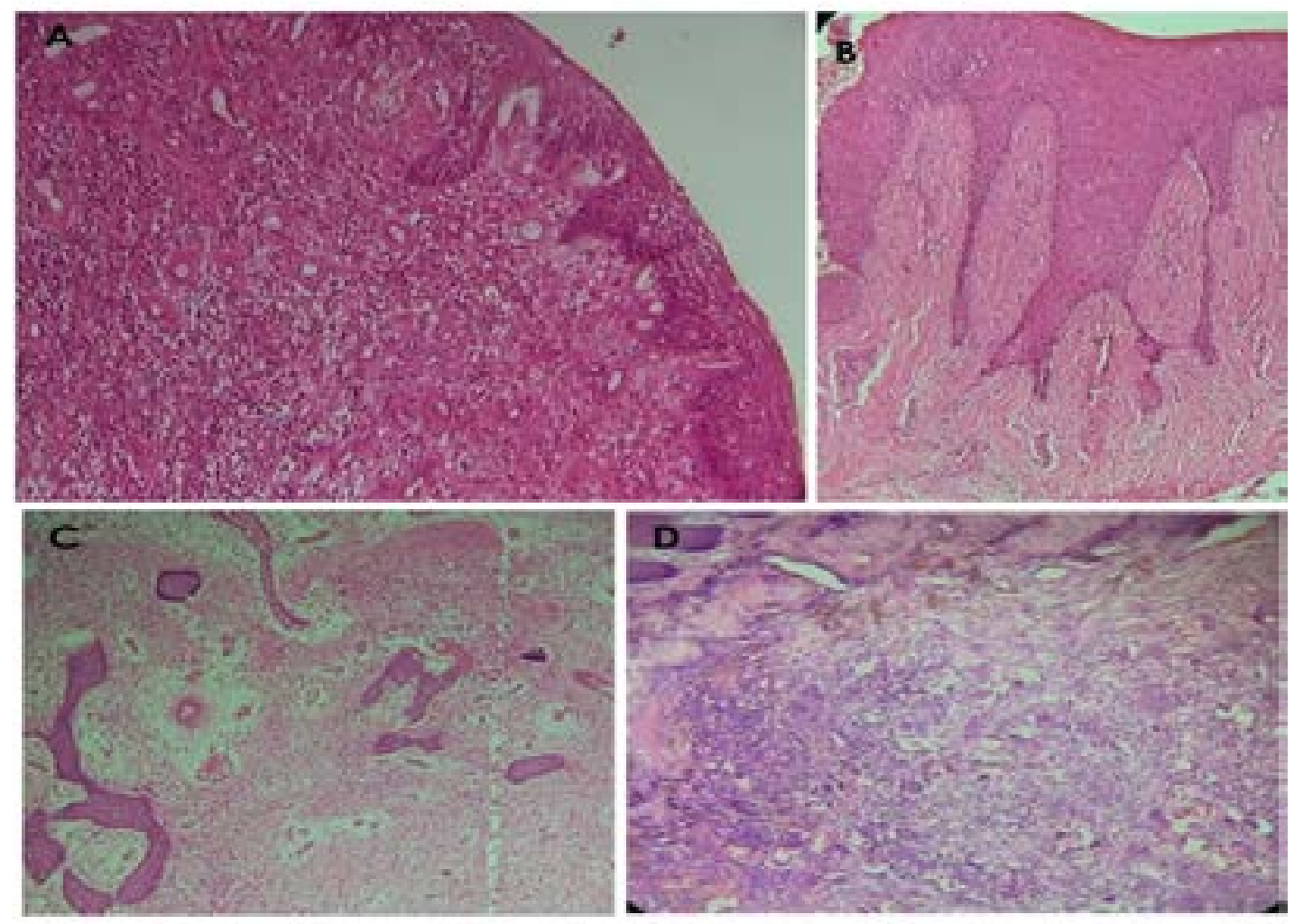

Figure 1: Photomicrographs of histological features oral reactive hyperplastic lesions. Histology shows numerous endothelial lined vascular channels and chronic inflammatory cellular influx within the underlying cellular fibrous connective tissue for pyogenic granuloma (A). Focal fibrous hyperplasia shows sparsely cellular, densely fibrous connective tissue (B). Peripheral ossifying fibroma demonstrated collagenized connective tissue stroma within which are found calcified osseous deposits $(\mathbf{C})$. Multinucleated giant cells were found within the cellular fibrous connective tissue of Peripheral giant cell granuloma (D). (Magnifications x40 (H\&E))

\section{Discussion}

RHLs constitute a group of lesions that are often observed in the oral environment as a result of physical insults from chronic irritation such as constant exposure to tissue injuries from masticatory, factitious and iatrogenic forces. This results into a hyperplastic tissue reaction in a vascular or fibrous tissue background and are clinically not easily distinguished from one another. These "tumor-like"lesions are not neoplastic, but they indicate a chronic process where an exaggerated reaction occurs (granulation tissue and formation of scar) following repair ${ }^{1}$.

The prevalence of the focal oral RHLs in our study was $20 \%$, similar to those previously reported in other studies $^{4-6}$. It is interesting to observe a much lower prevalence in a similar study by Effiom et al $(5.6 \%)^{7}$. This variation could possibly be explained by the length of study period and the level of oral hygiene awareness and plaque/calculus control among the urban population in their study area. Other studies ${ }^{2,9}$, similarly reported a lower prevalence of reactive lesions $(12.8 \%$, and $6.7 \%$ of all cases). However, much higher frequencies were observed in the study by Aghbali et al $(48 \%)^{13}$ and Hashemi et al, $(39 \%)^{14}$. The factors suggested to be responsible for this variation in prevalence of oral RHLs in different studies include: geographical and lifestyles differences; different nomenclatures applied to these lesions; racial factors; and the study population involved ${ }^{4-6,13}$. Furthermore, it has been observed that many oral RHLs may have been clinically diagnosed but not biopsied, which may affect appropriate diagnosis and treatment ${ }^{6}$. 
Several studies in the scientific literature have reported female predilection in oral RHLs ${ }^{7,9,13}$, and similar trends was observed in our study, with a female to male ratio of 2:1. This may be due to the fact that females are more concerned about dental care or that hormonal influence plays a part as well. The role of hormones has been demonstrated in pregnancy induced pyogenic granuloma; where there is exposure of inflamed gingival to progesterone and estrogen present in saliva and blood stream during pregnancy. It is believed that this could be the major contributory factor in the pathogenesis of pregnancy induced pyogenic granuloma ${ }^{7,13}$.

This study also revealed that the age distribution of reactive hyperplastic lesion was most frequent among the $2^{\text {nd }}$, $3^{\text {rd }}$ and $4^{\text {th }}$ decades of life which is in agreement with other reports $s^{5,9,13}$. Our observation of lower number of cases in the $7^{\text {th }}$ and $8^{\text {th }}$ decades may indicate that people in this age group are mostly edentulous or lacking motivation for regular dental visit ${ }^{9}$.

Ala Aghbali et $\mathrm{al}^{13}$, in their study of 197 cases of reactive hyperplastic lesions reported a mean age of $37.68 \pm 18.97$ years which was similar to our mean age of $37.7 \pm 21.1 \mathrm{yrs}$. Other studies have reported higher mean ages (Between 40-45 years) for oral RHLs ${ }^{15,16}$. It is also important to highlight that the highest prevalence of the lesion in this study was found in the age group 9-29 years old; while the oldest age groups $70-89$ years and $>90$ years, had the lowest prevalence. This is in agreement with the reports of other studies ${ }^{7,9,16}$. POF was observed in almost equal prevalence all through the age group. These findings are similar to the study of Effiom et al, where similar distributions was found according to age groups ${ }^{7}$.

The gingiva was the most common location for reactive lesions as observed in this study, presenting with $84.6 \%$ prevalence and greater predilection in the maxilla than the mandible. This is comparable with previous studies $^{2,5,16}$. The predominant gingival location of these lesions buttresses the fact that the periodontal ligament and connective tissue are pluripotential tissues containing cells capable of giving rise to most of the reactive lesions $^{5,17}$. However, buccal mucosa was found to be the second most frequent location for reactive hyperplastic lesions by most studies ${ }^{9,15,16}$. This is in contrast with our findings where the lips were found to be the $2^{\text {nd }}$ most frequent. This may confirm the fact that RHLs can be seen in any other sites susceptible to trauma however gingival is the most frequent location.
In this study, pyogenic granuloma (PG) was the commonest oral RHLs, which is in accordance with documented studies in literature ${ }^{5,7,9,18}$. PG presented with a prevalence of $43.6 \%$ in our study with a wide age range distribution which is comparable to the findings of other studies ${ }^{4,7}$.

Females were observed to be affected by PG more than males (1.4:1) with peak incidence seen in the second and third decades of life. This is consistent with previous reports in the scientific literature ${ }^{3,5,7}$. The female predilection of this lesion has been ascribed to the effect of female hormones, estrogen and progesterone, and its direct influence on the gingivae, which is a target organ for these hormones ${ }^{7}$.

Literature evidence demonstrates that the prevalence of pyogenic granuloma in pregnant women is about $5 \%{ }^{4}$, which is comparable to the findings in our study (in which $5.9 \%$ of cases of pyogenic granuloma were pregnancy induced). This however differs from the findings of the study of Effiom et $\mathrm{al}^{7}$, in which a higher value of 9.5\% was reported. Evidence from previous studies have shown that gingival tissues are rendered more susceptible to chronic irritation, especially by plaque and calculus via the interaction between the serum estrogen and progesterone concentrations in pregnancy ${ }^{12,16}$. Potent immunosuppressant effect of progesterone in pregnancy has also been implicated in the aetiopathogenesis of $\mathrm{PG}^{19}$.

The role of these hormones in the pathogenesis of pregnancy epulis has been further buttressed by the observation that PG is more clinically apparent as the level of these hormones heighten during pregnancy and it regresses when the serum level of the hormones return to normal, postpartum ${ }^{20,21}$.

Our study showed higher female proportion, most frequent age group, and maxillary gingival preponderance for FFH. This findings alludes to the notion that most inflammatory or reactive hyperplasia of gingiva may be a spectrum of the same lesion at different stages of histological maturation ${ }^{12}$. FFH is the second most common RHL with a prevalence of $39.74 \%$ in this study and this supports other studies ${ }^{5,7,18}$. However, this differs from other studies in the literature where FFH was reported as the most frequent RHLs ${ }^{2,4,9,13,14}$. This may be as a result of socio-economic and cultural variations, racial differences, different classification methods, available resources, and histopathologic case arrangement in lesions ${ }^{4}$. 
POF is a relatively uncommon solitary non-neoplastic gingival growth coined by Eversole and Rovin ${ }^{21}$. Different nomenclature has been ascribed to POF including peripheral fibroma with calcification and calcifying fibroblastic granuloma. Similar to other studies ${ }^{16,22}$, POF was the third most commonest RHL in this study. However, in other studies, 6 , POF was reported as the most frequent. Patil et $\mathrm{al}^{4}$, documented the lesion as the lowest occurrence in their study. POF represented $12.8 \%$ of the oral RLHs $2.56 \%$ of total biopsy in this study; which concurs with the report of Reddy et al that documented a frequency of $17.7 \%$ of the oral RHLs and $2.26 \%$ of the oral biopsy in their study ${ }^{9}$. The prevalent of POF in our study is higher than that of Patil et al $(9.7 \%)^{4}$. Previous reports have documented a female predilection of $\mathrm{POF}^{3,6}$, while few others have found male predominant ${ }^{4}$. Our study however found POF exclusively in females and almost entirely on the gingiva (90\%). The predominant gingival location potentiate the assertion that this lesion originate from the periodontal ligament which contains cells capable of producing bone and cementum ${ }^{21,22}$. It is important to note that multicentric pattern of presentation of POF have been observed in association with conditions involving genetic mutation such as nevoid basal cell carcinoma syndrome, multiple endocrine neoplasia (MEN) type II, neurofibromatosis and Gardner syndrome ${ }^{22}$. POF showed equal distribution across the age groups in our study which is not in support of the findings from other studies where a bimodal peak incidence of $2^{\text {nd }}$ and $3^{\text {rd }}$ decades were commonly reported as the most frequent age of presentation ${ }^{3,4,9}$. From our study, POF was discovered with a high frequency in the maxilla $(70 \%)$ which is in agreement to some studies ${ }^{2,3}$, but however contrasted by other who reported mandibular predilection ${ }^{6,7}$.

PGCG is an exophytic lesion that clinically resembles PG. It can be differentiated histologically by the presence of multinucleated giant cells seen in the connective tissue stroma. Its site of occurrence also supports a possible histological derivation from superficial periodontal ligament. Our study observed PGCG as the least common lesion with a prevalence of $3.85 \%$. This observation is similar to the findings of Effiom et al $(3.2 \%)^{7}$ and Kaur et al $(3.4 \%)^{16}$. Some studies found no gender predilection for PGCG3, while others documented a female predominance $^{7,16}$, as found in the present study. POF and PGCG occurred exclusively on the gingivae with female preponderance.

\section{Conclusion}

The frequency of RHL in this study was $20 \%$. The most common peripheral lesion was PG. The mean age of patients was $37.80 \pm 20.67$ years and reactive lesions were significantly more common in women. The most common locations of involvement was the gingiva with infrequent location in other intraoral sites. It was found that an appreciable level of relationship exists between the various histological types of oral RHLs. The similarities observed for different types of oral RHLs may allude to the fact that these lesions are possibly different stages in the continuum of the same traumatic/inflammatory pathology. In addition, the frequent gingival site of occurrence supports may also assert that these hyperplastic lesions are the same lesions at different developmental levels. Therefore familiarity with the frequency and presentation of these common oral lesions is beneficial in developing a clinical diagnosis and formulating a differential diagnosis. This would enable accurate patient evaluation and management when encountered in practice. So, early diagnosis and surgical excision of these lesions along with removal of the irritant can greatly minimize potential complications.

Considering the similarities in RHLs, emphasis should be directed towards the best treatment modality, so as to solve the problem of high recurrence rate after the treatment of some of the lesions, particularly in the dentulous areas of the mouth. A future study directed towards determining the safest stage for the surgical excision and curettage in relation to the histological types would be beneficial, in order to prevent recurrence after treatment. One limitation of our study is the fact that the data was only generated from a single centre. Also, being a retrospective study, the records used were not specifically designed for our study, and this may affect the quality of retrieved data.

\section{Acknowledgement}

HAA thanks the South African Medical Research Council (SAMRC) for a mid-career scientist research grant.

\section{Conflict of interest}

The Authors declare that they have no conflict of interest. 


\section{Authors' contributions}

OOS conceptualized, designed, prepared and critically revised the manuscript, tables and figures. KEA, OMA, AML, ASO, AOA, were involved in the design, data collection/analysis, and preparation of sections of the manuscripts. HAA was involved in the design, critical intellectual revision and finalization of the manuscript, figures and tables. All authors had final approval of the submitted.

\section{Reference}

1. Shadman N, Ebrahimi SF, Jafari S, Eslami M. Peripheral giant cell granuloma: a review of 123 cases. Dent Res J (Isfahan). 2009;6(1):47-50.

2. Buchner A, Shnaiderman-Shapiro A, Vered M. Relative frequency of localized reactive hyperplastic lesions of the gingiva: a retrospective study of 1675 cases from Israel. Journal of oral pathology \& medicine: official publication of the International Association of Oral Pathologists and the American Academy of Oral Pathology. 2010;39(8):631-8.

3. Kfir Y, Buchner A, Hansen LS. Reactive lesions of the gingiva. A clinicopathological study of 741 cases. Journal of periodontology. 1980;51(11):655-61.

4. Patil S, Maheshwari, S., Khandelwal, S., Wadhawan, R., Somashekar, SB., Deoghare, A. . Prevalence of reactive hyperplastic lesions of the gingiva in the Western Indian population. Journal of Orofacial Sciences. 2014;6(1):41-5.

5. Kadeh H, Saravani S, Tajik M. Reactive hyperplastic lesions of the oral cavity. Iran J Otorbinolaryngol. 2015;27(79):137-44.

6. Maturana-Ramirez A, Adorno-Farias D, Reyes-Rojas M, Farias-Vergara M, Aitken-Saavedra J. A retrospective analysis of reactive hyperplastic lesions of the oral cavity: study of 1149 cases diagnosed between 2000 and 2011, Chile. Acta Odontol Latinoam. 2015;28(2):103-7.

7.Effiom OA, Adeyemo WL, Soyele OO. Focal Reactive lesions of the Gingiva: An Analysis of 314 cases at a tertiary Health Institution in Nigeria. Niger Med J. 2011;52(1):35-40.

8. daSilva FC, Piazzetta CM, Torres-Pereira CC, Schussel JL, Amenabar JM. Gingival proliferative lesions in children and adolescents in Brazil: A 15-year-period cross-sectional study. J Indian Soc Periodontol. 2016;20(1):63-6.

9. Reddy NR, Kumar PM, Selvi T, Nalini HE. Management of Recurrent Post-partum Pregnancy Tumor with Localized Chronic Periodontitis. Int J Prev Med. 2014;5(5):643-7.
10. Weir JC, Davenport WD, Skinner RL. A diagnostic and epidemiologic survey of 15,783 oral lesions. Journal of the American Dental Association. 1987;115(3):439-42.

11. Esmeili T, Lozada-Nur F, Epstein J. Common benign oral soft tissue masses. Dent Clin North Am. 2005;49(1):22340, $\mathrm{x}$.

12. Daley TD, Nartey NO, Wysocki GP. Pregnancy tumor: an analysis. Oral Surg Oral Med Oral Pathol. 1991;72(2):1969 .

13. Ala Aghbali A, Vosough Hosseini S, Harasi B, Janani M, Mahmoudi SM. Reactive hyperplasia of the oral cavity: a survey of 197 cases in tabriz, northwest iran. J Dent Res Dent Clin Dent Prospects. 2010;4(3):87-9.

14. Hashemi Pour M, Rad, M., Mojtahedi, A. A Survey Of Soft Tissue Tumor-Like Lesions Of Oral Cavity: A Clinicopathological Study. Iranian Journal of Pathology. 2008;3(2):81-7.

15. Hunasgi S, Koneru, A., Vanishree, M., Manvikar, V., Patil, AM., Gottipati, H. Retrospective analysis of the clinical features of 530 cases of reactive lesions of oral cavity. Journal of Advanced Clinical \& Research Insights. 2014;1:1-6. PubMed.

16. Kaur M, Singh, S., Singh, R., Singh, A., Singh, R. Reactive Hyperplastic Lesions of the Oral Cavity: A Retrospective Analysis in Jammu Region of Jammu and Kashmir State, India. International Journal of Scientific Study. 2016;4(4):92-6.

17. Naderi NJ, Eshghyar N, Esfehanian H. Reactive lesions of the oral cavity: A retrospective study on 2068 cases. Dent Res J (Isfahan). 2012;9(3):251-5.

18. Jafarzadeh H, Sanatkhani M, Mohtasham N. Oral pyogenic granuloma: a review. Journal of Oral Science. 2006;48(4):167-75.

19. Ojanotko-Harri AO, Harri MP, Hurttia HM, Sewon LA. Altered tissue metabolism of progesterone in pregnancy gingivitis and granuloma. Journal of clinical periodontology. 1991;18(4):262-6.

20. Bataineh A, Al-Dwairi ZN. A survey of localized lesions of oral tissues: a clinicopathological study. J Contemp Dent Pract. 2005;6(3):30-9.

21. Eversole LR, Rovin S. Reactive lesions of the gingiva. J Oral Pathol. 1972;1(1):30-8.

22. Ramu S, Rodrigues, C. Reactive hyperplastic lesions of the gingiva: A retrospective study of 260 cases. World J Dent. 2012;3:126-30. PubMed. 